\title{
Crowd-Sourced Filmmaking: Despair is Your Friend
}

\author{
Mitchell Rose, The Ohio State University
}

OK, now stay calm! I want you to push the red lever forward... SLOWLY!!!

If the pilot of a 767 died, could you land the plane while the control tower talked you through it over the radio? I've always been fascinated (obsessed) by the idea of getting people to do complicated things, remotely, via instructions. And that's what I wanted to undertake when I made my new crowd-sourced film, Globe Trot.

I got 54 filmmakers in 23 countries (representing all seven continents including Antarctica) to each contribute two seconds of precise footage that I edited together. 15 months of work, resulting in a 3-minute film. Have a look.

A second impetus for this project was experimentation I've been doing the last few years in what we could call "Hyper-Matchcutting"-films where every adjacent edit is perfectly aligned in position and continuity. My first foray into this was my film Advance.

Of course there's nothing new in this. Buster Keaton did it so brilliantly 90 years ago in Sherlock, Jr.

And I experimented more with this in my film Contact.

Film is about change, and I found that these Hyper-Matchcutting explorations only heightened that dynamic of change, keeping the spectator engaged. The story is progressing but the characters and locations are shifting-don't blink because the new is unfolding.

The question then was, could I make a Hyper-Matchcutting film in which I applied this notion of remote collaboration? Could I get distant filmmakers and performers to collaborate at a high level of complexity ... via instructions? My idea was to take a dance and assign four counts of it to filmmakers around the world. They would teach these four counts to someone, film it, and send me the footage for assembly.

And I wanted to use non-dancers. The premise was: Anyone can learn two seconds of even complicated choreography if you take the time to teach them and work with them. Three seconds? That may be pushing it. But two seconds... probably. I like seeing non-dancers perform sophisticated choreography, a bit awkwardly, but trying their best. And my hope was, that seeing people all over the world participating in a single 
choreographic thread, there would be a sense of unity in it-a sense of the democratization of dance.

My original plan was to enroll ten filmmakers around the world-sort of a who's who in dance-film-and have them each shoot 10 phrases. But knowing that each phrase might require several dozen shots until you get a good one, it seemed unreasonable to ask these 10 filmmakers to do this much work-particularly since I couldn't pay them what they'd really be worth. Even a pittance, times 10, is a lot.

But then I got an idea! Why not crowd-source this? Instead of getting 10 people to commit to doing 10 phrases, get a lot of volunteers to each do one. Sure, just crowdsource it! That'll be simple! Right.

The first step was to choreograph the dance and I enlisted Bebe Miller, my colleague at Ohio State University. I described to her the quality of movement I'd like the dance to have: a simple non-technical jauntiness. In the studio Bebe sketched out some movement and the project assistant, Ellie Escosa-Carter, followed along, learning and recording. I was amazed by the speed with which Bebe can work. It's often said that there should be no self-censorship when brainstorming, and it felt like our choreographic sessions were a sort of brainstorming. Movement would pour out of Bebe with great spontaneity, and then we'd go back and refine and shape the form.

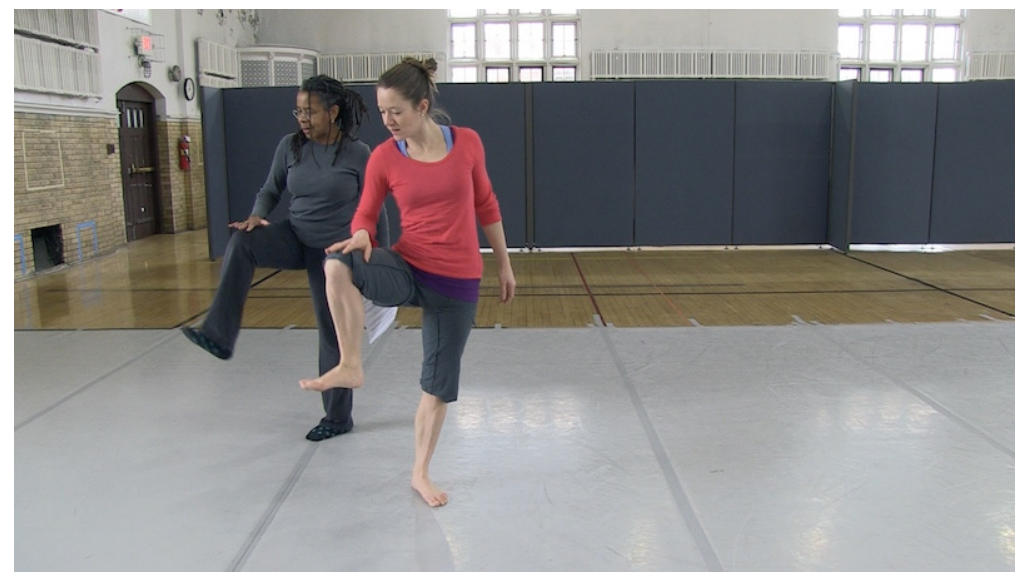

Bebe Miller ( $L$ ) and project assistant Ellie Escosa-Carter choreographing Globe Trot. (frame grab)

Next was testing the editing effect, to see if the concept was working visually. Ellie and I grabbed people walking around the university and taught them a little movement very quickly.

Then I had to create a manual to train the filmmakers. The challenge was to make it as concise as possible. I could have gone into excruciating detail-and oh, I can do thatbut I'd be working with volunteer filmmakers who'd lose interest if I just gave them 
dozens of pages to read. You can see the manual and training materials here: http://www.mitchellrose.com/globetrot/

The next challenge was finding filmmakers around the world to participate. It's not easy finding people to work just for love and it was months of searching ... more accurately, groveling ... utilizing social media and contacts from dance-film festival curators.

Eventually I had found 54 filmmakers.

Each filmmaker was sent their four-count phrase and a kit of materials that included a spreadsheet that showed where the performer should be in the frame. The frame was divided into ninths ...

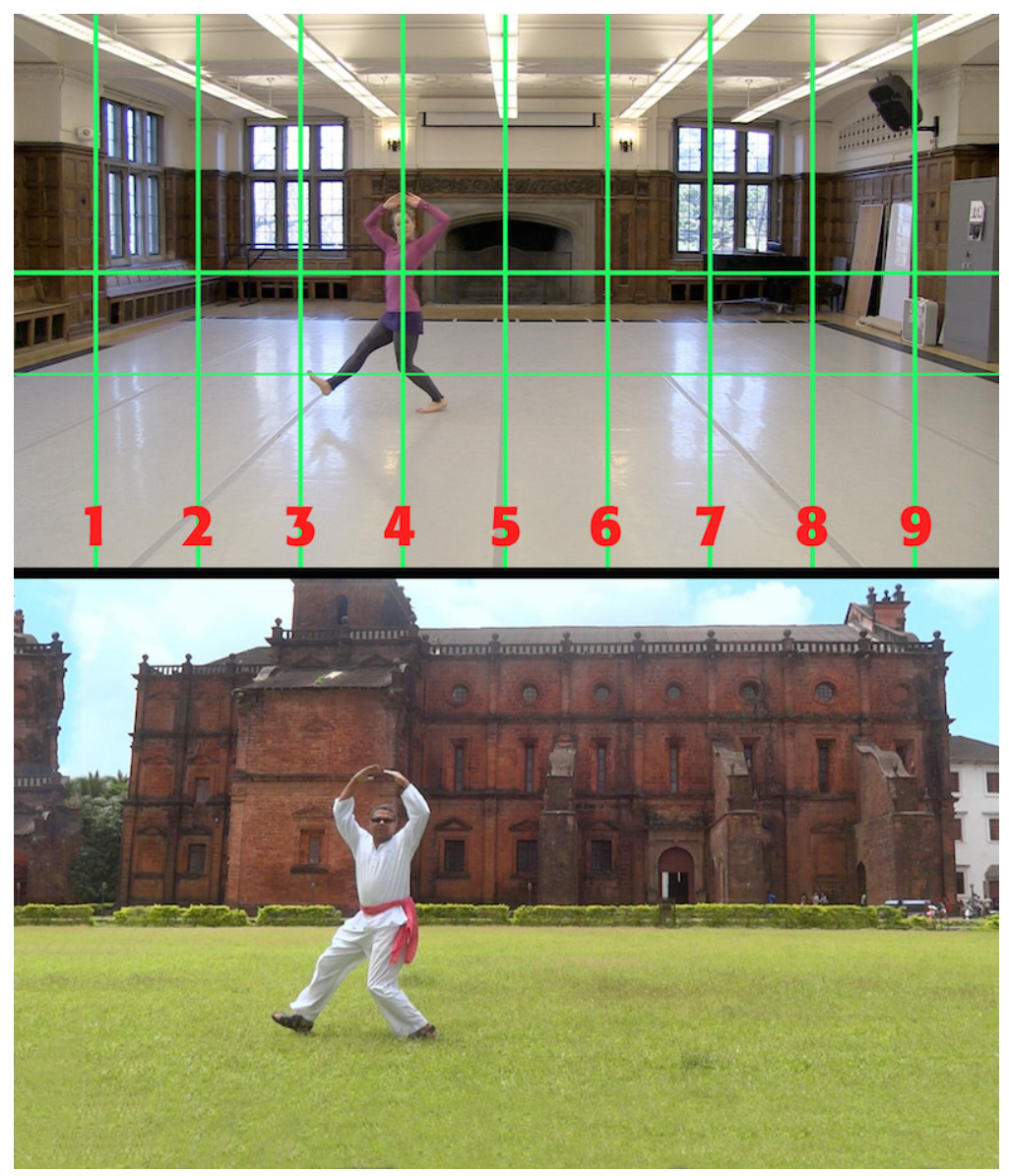

Ellie Escosa-Carter in an image from the Globe Trot manual compared to performer Krishna Kapadia in Goa, India. (frame grabs)

... and so if you were assigned Measure 4, Counts 2, 3, 4, 5, your chart would show you that for those counts the performer should hit marks $5,6,6,5$. 
A deadline of two months was set. The clips began to roll in. And I panicked. The first shots I got were incredibly off-placement wrong, choreography wrong. Utterly unusable. I feared all this work was for naught.

But then a few more came in, and though not perfect, they were close. Close enough that a little dialogue with a filmmaker willing to reshoot could get what was needed. And so began The Summer of Emails as I sent over a thousand emails offering critiques of footage and clarifying instructions for the filmmakers.

Some filmmakers sent in a few clips, some sent in dozens (God bless them). And eventually I got enough to work with -561 shots for the 111 the film needed. Imperfect placement? That's inevitable. But I could tweak the clips in editing.

I can't tell you the affection I feel for my filmmakers. Why would they do this? I don't understand it. But they stuck with it-this community around the world who've never met-and they delivered.

I'm very happy with Globe Trot and the film means a lot to me. I've made 25 films over the course of my career. I've done funny, I've done dramatic and conceptual and beautiful... but I've never done joyous. And it feels good to do so in a celebration of humanity. I remember when I first showed a rough cut to Bebe, her reaction was, "I love people!" That's exactly the response I want.

This technique of Hyper-Matchcutting has the effect of creating equalization. When a new image takes the place of an old image, with the same continuity of action, it says, "These things are equal." And that's what I hope the message of Globe Trot is-that people, all over the world, are equal.

\section{Biography}

Prior to becoming a filmmaker, Mitchell Rose was a New York-based choreographer. His company toured internationally for 15 years. Eventually he was drawn more to visual media and chose to become a filmmaker, entering The American Film Institute as a Directing Fellow. Since A.F.I., his films have won 69 festival awards and are screened around the world.

The New York Times called him: "A rare and wonderful talent." The Washington Post wrote that his work was "in the tradition of Chaplin, Keaton, and Tati-funny and sad and more than the sum of both." 
Mr. Rose tours a program called The Mitch Show, an evening of his short films together with audience-participation performance pieces. In 2009 he toured The Mitch Show in Kosovo as a U.S. State Dept. Cultural Envoy.

Mr. Rose is currently an assistant professor of dance-filmmaking at Ohio State University.

\section{References}

Advance. Dir. Mitchell Rose. Chor. and perf. Ashley Roland and Jamey Hampton. Comp. William Goodrum. Prod. Red Red Rose Pictures and BodyVox. 2009. Vimeo.

Contact. Dir. Mitchell Rose. Chor. Ashley Roland and Jamey Hampton. Comp. William Goodrum. Prod. Mitchell Rose and BodyVox. 2012. Vimeo.

Globe Trot. Dir. Mitchell Rose. Chor. Bebe Miller. Comp. William Goodrum. Prod. Mitchell Rose. 2013. Vimeo.

Rose, Mitchell. "Globe Trot." Mitchell Rose: Filmmaker. Accessed 31 Jan. 2015. www.mitchellrose.com/globetrot

Rose, Mitchell and Bebe Miller. "'Globe Trot' test-1 second clips." 2013. Vimeo. "Join Us for Globe Trot." 2014. Vimeo.

Sherlock, Jr. (1924) Dir. Buster Keaton. Prod. Buster Keaton Productions. YouTube Accessed 31 Jan. 2015. 